\title{
ENRICHMENT OF FRUIT LEATHERS WITH BERRY PRESS CAKE POWDER INCREASE PRODUCT FUNCTIONALITY
}

\author{
Jonas Viskelis, Marina Rubinskiene*, Ceslovas Bobinas, Ramune Bobinaite \\ Institute of Horticulture, Lithuanian Research Centre for Agriculture and Forestry, Kauno st. 30, LT-54333, Babtai, Kaunas reg., \\ Lithuania, e-mail: m.rubinskiene@lsdi.lt
}

\begin{abstract}
Fruit leathers are tasty, chewy, dehydrated fruit products which are eaten as snack or dessert. Dried berry press cake powders could be a promising ingredient for enhancing nutritional value of such products. The aim of this work was to enrich apple and black currant fruit leather with dried blackcurrant and raspberry press cake powders, and to evaluate the effect of the press cake additives on the content of total phenolics, total anthocyanins, antioxidant activity and textural properties of the product (fruit leathers). In this study, fruit leather made of apple and black currant puree was enriched with two different berry press cake powders (1) freeze-dried raspberry press cake powder (dry-matter content 97.3\%) (2) conventionally dried black currant press cake powder (dry-matter content $95.4 \%$ ). The contents of total phenolics, total anthocyanins, antioxidant activity, colour and textural properties of the test samples was evaluated. The content of phenolic compounds in raspberry and black currant press cake powders was 28.5 and $25.4 \mathrm{mg} \mathrm{g}^{-1}$ respectively. The content of anthocyanins in black currant press cake powder was more than 19-fold higher than in raspberry press cake powder. The addition of berry press cake powder reduced hardness of the fruit leathers and samples with black currant press cake powder was two times softer than the control. Raspberry press cake additive increased the lightness $\left(\mathrm{L}^{*}=24.0\right)$ and the redness $\left(\mathrm{a}^{*}=3.4\right)$, whereas black currant press cake powder reduced the lightness $\left(\mathrm{L}^{*}=22.5\right)$ and the redness $\left(\mathrm{a}^{*}=1.5\right)$ of the product. The content of anthocyanins in the fruit leathers enriched with black currant press cake powder was significantly higher than in control sample (116.4 and $74.1 \mathrm{mg} 100 \mathrm{~g}^{-1}$, respectively). Berry press cake powder also increased antioxidant capacity of the fruit leathers. The results of the study can be useful for health-conscious food producers and consumers.
\end{abstract}

Keywords: fruit leathers, berry press cakes, phenolic, products, texture.

\section{Introduction}

Fruit leather is a dehydrated, dietary fruit product which is often eaten as snack or dessert. Fruit leathers are restructured fruit made from fresh fruit pulp or a mixture of fruit juice and other ingredients that involves a dehydration step (Huang, Hsieh, 2005). During manufacturing, fruit pulps are mixed with sugar, pectin, acid, and colourants and then dried into sheet-shaped products. Most fruit leathers are dried at 30 to $80{ }^{\circ} \mathrm{C}$ for up to 24 hours until the target moisture content (12-20\%) is reached (Quintero Ruiz et al., 2012; Diamante et al., 2014). Fruit leathers are nutritious, tasty and retain substantial quantities of minerals, vitamins, and phenolic phytochemicals that are initially present in raw materials (fruits, berries and vegetables) (Diamante et al., 2014).

An important portion of fruits and berries are processed into juice, which generates high amounts of by-product (press cake residues). Berry press cake (pomace) comprises berry skins and seeds, which contain fibres and various bioactive substances (Kruczek et al., 2016). The levels of phenolic antioxidants in fruit and berry processing wastes are usually found to be higher than in the actual product itself (Tian, 2016). Epidemiological studies confirmed that consumption of phenolic phytochemicals reduces the risk of cardiovascular diseases, cancer, and other degenerative diseases (Shahidi, 1997).

Nowadays, food is not merely viewed as a source of essential nutrients to ensure proper growth and development, but as a route to optimal wellness. Because of the rising interest in functional foods, scientists and food producers are looking for new sources of bioactive substances and also carriers of those substances. One of the possibilities to increase the content of natural antioxidants in the diet is to enrich food products with concentrated fractions of plant polyphenolic compounds. For instance, it was reported that grape seed and peel extract additive improved biochemical composition and functional properties of the grape juice (Ghafoor et al., 2011). Furthermore, it was suggested that raspberry seed extract can be suitable antioxidant added to muesli and cereal products (Klensporf, Jelen, 2008). In the study reported by Gailite et al. (2006) raspberry marc was used to improve the nutritional value of wheat bread. The results showed that the contents of fibre, carotenoids and vitamin E were higher in wheat bread with berry marc additive (Gailite et al., 2006). Partial replacement of wheat flour with the raspberry and black currants press cake powders increased the amount antioxidants and dietary fibre in the cookies (Górecka et al., 2010; Molnar et al., 2015). The antioxidant rich raspberry marc extract added to different fruit purees increased their functionality (Bobinaite et al., 2016).

The aim of this work was to enrich apple and black currant fruit leather with dried black currant and raspberry press cake powders, and to evaluate the effect of the press cake additives on the content of total phenolics, total anthocyanins, antioxidant activity and textural properties of the product (fruit leathers).

\section{Materials and Methods}

Fruit puree preparation

Fresh fruits and berries were blanched and their edible part was separated and pureed using machine EP1000 (Voran Maschinen GmbH, Pichl bei Wels, Austria). Fruit purees were prepared using standardized recipes developed in biochemistry and technology laboratory of Institute of Horticulture LRCAF.

Apple / black currant puree was prepared by blending $78.0 \%$ of apple puree and $16.5 \%$ of black currant puree, 
and adding $5.5 \%$ of sugar (control sample). Prepared puree was then enriched with either $1 \%$ of milled, freeze-dried raspberry press cake powder or $2 \%$ milled, conventionally (convection drying) dried black currant press cake powder.

\section{Drying of fruit puree}

Apple / black currant leathers were made by pouring pureed fruit onto a flat surface for drying. Fruit puree was dried using a convection drying method and performed in a UDS-150/1 hot-air laboratory dryer (Utena, Lithuania) at a temperature of $55 \pm 2{ }^{\circ} \mathrm{C}$ and an air-flow rate of $1.5 \mathrm{~m} \mathrm{~s}^{-1}$. After drying fruit leathers were cut into strips.

\section{Colour and texture measurement}

The colour of raspberry and black currant press cake powders and fruit leathers was measured with a spectrophotometer MiniScan XE Plus (Hunter Associates Laboratory, Inc., Reston, Virginia, USA). In the reflectance mode, CIE L*a*b* colour parameters were recorded as $\mathrm{L}^{*}$ (lightness), $\mathrm{a}^{*}$ (+ redness), and $\mathrm{b}^{*}$ (+ yellowness). The chroma $\left(\mathrm{C}=\left(\mathrm{a}^{* 2}+\mathrm{b}^{* 2}\right)^{1 / 2}\right)$ and hue angle $\left(\mathrm{h}^{\circ}=\arctan (\mathrm{b} * / \mathrm{a} *)\right)$ were also calculated (McGuiere, 1992). The total colour differences $(\Delta \mathrm{E})$ between dried fruit leather without additives and with berry press cake powder additive were calculated using following formula:

$$
\Delta E=\sqrt{\left(\Delta L^{*}\right)^{2}+\left(\Delta a^{*}\right)^{2}+\left(\Delta b^{*}\right)^{2}}
$$

Data was presented as the average of three measurements. Colour coordinates were processed with the program Universal Software V.4-10.

The texture of fruit leathers was measured using a TA.XTplus Texture Analyzer (Stable Micro Systems, Godalming, England), with $2 \mathrm{~mm}$-diameter flat head probe. The analysis data was processed with "Texture Exponent" program.

\section{Extract preparation}

Dried berry press cake was ground in an ultracentrifugal rotor mill Retsch ZM200 (Retsch, Haan, Germany) using $0.2 \mathrm{~mm}$ particle size sieve, then 5 grams of powder was extracted with $50 \mathrm{~mL}$ of $70 \%$ methanol at room temperature for 60 min under constant shaking (Sklo Union LT, Teplice, Czech Republic). After decantation the residue was re-extracted second time under the same conditions. The combined extracts were filtered and subjected to further analysis.

Dried fruit leather $(5 \mathrm{~g})$ was added to $50 \mathrm{~mL}$ of $70 \%$ methanol and homogenized using Polytron PT 1200E homogenizer (Kinematica, Luzern, Switzerland). The extraction was carried out at room temperature for 120 min under constant shaking. The extract was then filtered and analysed.

Analysis of total anthocyanins, total phenolics and antioxidant activity

The content of total phenolic compounds in the extracts of dried berry press cake powders and dried leathers was measured using the Folin-Ciocalteu procedure (Slinkard, Singleton, 1977). The total anthocyanins content in the extracts of dried berry press cake powders and dried leathers was determined using the pH differential method (Giusti, Wrolstad, 2003). The concentration of anthocyanins was expressed in $\mathrm{mg}$ of cyanidin-3-glucoside in $100 \mathrm{~g}$ of press cake powder or fruit leather (dry weight, d.w.).

Three different methods were used to test the antioxidant activity of the methanolic fruit leather extracts: FRAP assay (Ferric reducing antioxidant power) (Benzie, Strain, 1996), DPPH radical scavenging assay (1,1-diphenyl-2-picryl hydrazyl radical reducing power) (Brand-Williams, 1995), and ABTS (2,2'-azino-bis-3-ethylbenzthiazoline-6-sulphonic acid) assay (Re et al., 1999).

Antioxidant activity of the samples was expressed in micromoles $(\mu \mathrm{mol})$ of Trolox equivalents (TE) per one gram of dried (d.w.) fruit leather.

\section{Statistical analysis}

All measurements were performed in triplicate and data was reported as mean \pm standard deviation. Mean values were further compared using Turkey's test, and differences were considered to be statistically significant when $\mathrm{p}<0.05$.

\section{Results and Discussion}

The chemical composition of dried berry press cake powders is presented in Table 1 . The content of phenolic compounds was extremely high in both investigated press cake powders. The content of total phenolics in freeze-dried raspberry press cake powder was only slightly higher than in dried black currant press cake powder. However, the amount of total anthocyanins in raspberry and black currant press cake powder was significantly different. The concentration of anthocyanins in the dried black currant press cake powder was almost 19 times higher than in freeze-dried raspberry press cake powder. These findings are not surprising since anthocyanins account for up to $80 \%$ of the total phenolic compounds present in black currants (Borges et al., 2010; Anttonen, Karjalainen, 2006), whereas the major phenolic compounds found in red raspberries are ellagitannins (Määttä-Riihinen et al., 2004; Vrhovsek et al., 2008). The strong positive correlation between total phenolics content and ellagitannins of raspberries was reported in different studies (Anttonen, Karjalainen, 2005; Bobinaite et al., 2012).

It is worth noting that anthocyanins in the food industry are increasingly utilized not only as natural colorants (E163) substituting synthetic colorants, but also because of their biofunctional properties.

The chemical composition of dried fruit leathers is presented in Table 2. The dry matter content of fruit leathers was very similar. As it was mentioned in the introduction the moisture content of fruit leathers should not be higher than 20\% (Diamante et al., 2014) since the preservation of fruit leathers depends on residual moisture content. The moisture content of the investigated fruit leathers varied from 16.1 to $17.8 \%$. 
Total phenolics, anthocyanins and dry-matter content of berry press cake powders

\begin{tabular}{|c|c|c|c|}
\hline Examples & $\begin{array}{c}\text { Anthocyanins, mg } 100 \mathrm{~g}^{-1} \\
\text { (d.w.) }\end{array}$ & $\begin{array}{l}\text { Phenolics, mg } 100 \mathrm{~g}^{-1} \\
\text { (d.w.) }\end{array}$ & $\begin{array}{c}\text { Dry-matter content, } \\
\% \\
\end{array}$ \\
\hline Raspberry press cake powder & $134.02 \pm 5.39^{\mathrm{b}}$ & $2846.9 \pm 145^{\mathrm{a}}$ & $97.3 \pm 0.05^{\text {ba }}$ \\
\hline Black currant press cake powder & $2539.4 \pm 19.09^{a}$ & $2428.2 \pm 114^{\mathrm{b}}$ & $95.4 \pm 0.06^{\mathrm{ba}}$ \\
\hline
\end{tabular}

Different letters in the same column indicates significant differences between the means ( $\mathrm{p} \leq 0.05)$.

Table 2

Total phenolics, total anthocyanins and dry-matter content of dried fruit leathers

\begin{tabular}{|c|c|c|c|}
\hline Samples & Anthocyanins, mg $100 \mathrm{~g}^{-1}$ (d.w.) & Phenolics, mg $100 \mathrm{~g}^{-1}$ (d.w.) & Dry-matter content, \% \\
\hline Control & $74.1 \pm 2.21^{\mathrm{c}}$ & $949.36 \pm 11.0^{\mathrm{bc}}$ & $83.7 \pm 0.06^{\mathrm{bc}}$ \\
\hline $\mathrm{RP}$ & $80.5 \pm 4.10^{\mathrm{b}}$ & $961.76 \pm 15.41^{b}$ & $83.9 \pm 0.05^{\mathrm{bc}}$ \\
\hline $\mathrm{BC}$ & $156.37 \pm 7.39^{\mathrm{a}}$ & $1001.98 \pm 25.74^{\mathrm{a}}$ & $82.2 \pm 0.02^{\mathrm{b}}$ \\
\hline
\end{tabular}

$\mathrm{RP}$ - fruit leather with raspberry press cake powder; BC - fruit leather with black currant press cake powder.

Different letters in the same column indicates significant differences between the means $(\mathrm{p} \leq 0.05)$.

Antioxidant activity of fruit leathers, $\mu \mathrm{mol} \mathrm{TE} \mathrm{g}^{-1}$ (d.w.)

\begin{tabular}{lccc}
\hline Samples & DPPH & FRAP & ABTS \\
\hline Control & $19.0 \pm 0.57^{\mathrm{b}}$ & $33.3 \pm 0.17^{\mathrm{c}}$ & $72.9 \pm 0.92^{\mathrm{c}}$ \\
RP & $20.1 \pm 0.97^{\mathrm{a}}$ & $36.9 \pm 1.20^{\mathrm{b}}$ & $74.9 \pm 0.23^{\mathrm{b}}$ \\
BC & $21.3 \pm 0.33^{\mathrm{a}}$ & $38.0 \pm 0.50^{\mathrm{a}}$ & $80.0 \pm 1.31^{\mathrm{a}}$ \\
\hline
\end{tabular}

RP - fruit leather with raspberry press cake powder; $\mathrm{BC}$ - fruit leather with black currant press cake powder. Different letters in the same column indicates significant differences between the means $(\mathrm{p} \leq 0.05)$.

Table 4

CIEL* $a^{*} b^{*}$ colour parameters of dried fruit leathers

\begin{tabular}{lccccc}
\hline \multicolumn{1}{r}{ Samples } & $\mathbf{L}^{*}$ & $\mathbf{a}^{*}$ & $\mathbf{b}^{*}$ & $\mathbf{h}^{\circ}$ & $\Delta \mathbf{E}$ \\
\hline Control & $23.9 \pm 0.79^{\mathrm{a}}$ & $2.1 \pm 0.17^{\mathrm{b}}$ & $0.4 \pm 0.18^{\mathrm{b}}$ & $349.7 \pm 4.67^{\mathrm{a}}$ & - \\
RP & $24.0 \pm 0.97^{\mathrm{a}}$ & $3.4 \pm 0.84^{\mathrm{a}}$ & $0.1 \pm 0.32^{\mathrm{a}}$ & $0.8 \pm 4.63^{\mathrm{c}}$ & $1.33^{\mathrm{b}}$ \\
BC & $22.5 \pm 1.95^{\mathrm{b}}$ & $1.5 \pm 0.31^{\mathrm{c}}$ & $0.6 \pm 0.27^{\mathrm{b}}$ & $337.3 \pm 10.1^{\mathrm{b}}$ & $1.82^{\mathrm{a}}$ \\
\hline
\end{tabular}

$\mathrm{RP}$ - fruit leather with raspberry press cake powder; $\mathrm{BC}$ - fruit leather with black currant press cake powder. Different letters in the same column indicates significant differences between the means $(\mathrm{p} \leq 0.05)$.

Higher contents of total phenolics and total anthocyanins were detected in the fruit leathers enriched with dried berry press cake powders. Higher content of anthocyanins and phenolics compounds was found in the fruit leather with dried black currant press cake powder. The content of total phenolics was by 1.3 and $5.5 \%$ higher in the fruit leathers enriched with raspberry and black currant press cake powder, respectively (Table 2). The content of total anthocyanins in the fruit leather enriched with dried black currant press cake powder was more than 2 times higher compared to control sample (fruit leather without berry press cake additive). Compared to control sample, the content of total anthocyanins in the fruit leather enriched with freeze-dried raspberry press cake powder was by $8.6 \%$ higher.

The berry press cake powders also increased antioxidant activity of the investigated fruit leathers (Table 3 ). The highest antioxidant activity possessed fruit leathers enriched with dried black currant press cake powder. The antioxidant activity of fruit leathers enriched with dried black currant press cake powder was by 9.7, 12.1 and $14.1 \%$ higher (ABTS, DPPH and FRAP assay, respectively) compared to the control sample. Compared to control sample, the antioxidant activity of fruit leathers enriched with raspberry press cake powder was by $2.7,5.8$ and $10.8 \%$ higher (determined by ABTS, DPPH and FRAP assay, respectively).

The lower antioxidant activity of fruit leathers with raspberry press cake powder compared to black currant press cake powder enriched product most probably is only due to the lower percentage of raspberry press cake powder used. Anthocyanins appear to be the main contributors to the antioxidant potential of black currants (Bordonaba, Terry, 2012; Borges et al., 2010). As reported previously, although raspberries had a lower content of anthocyanins than black currants there was only a slight difference in the antioxidant capacities of those two berries (Borges et al., 2010). The authors concluded that high antioxidant capacity of raspberries is because of the presence of the ellagitannins sanguine H-6 and lambertianin C, which were responsible for 58\% of the total antioxidant capacity of raspberries (Borges et al., 2010). Furthermore, it has been shown that the content of ellagitannins was considerably higher in raspberry press cake extracts than in fruit or fruit pulp extracts (Bobinaitè et al., 2013).

The colour measurement results of dried fruit leathers are presented in Table 4 . The raspberry press cake powder additive increased the lightness $\left(\mathrm{L}^{*}\right)$ and redness (a*) of fruit leather, whereas the black currant press cake powder reduced the lightness $\left(\mathrm{L}^{*}\right)$ and redness $\left(\mathrm{a}^{*}\right)$ of the product. Furthermore, black currant press cake 
powder shifted the colour of the fruit leather slightly more to the blue (reduced $b^{*}$ value). The fruit leather with black currant press cake powder additive was the darkest.

The colour difference $(\Delta \mathrm{E})$, between control fruit leather and fruit leathers enriched with berry press cake powders, shows that black currant press cake powder additive changed the colour of the control (apple/black currant) fruit leather more noticeably than freeze-dried raspberry press cake powder (Table 4).

The press cake powder additive had significant influence on the texture properties of dried fruit leathers (Figure 1).

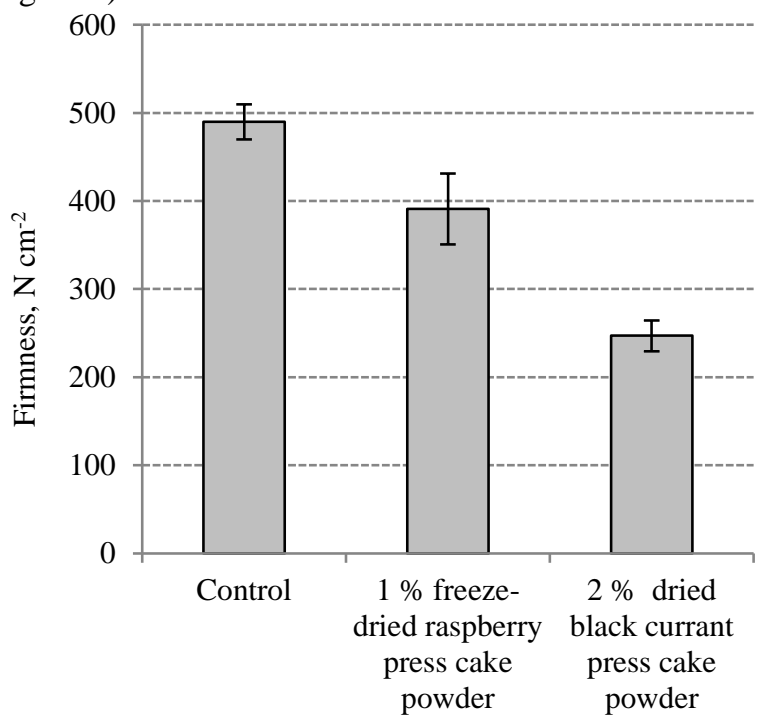

Figure 1. Firmness of dried fruit leathers

The addition of freeze-dried raspberry press cake powder reduced firmness of the fruit leather from 489.78 to $390.9 \mathrm{~N} \mathrm{~cm}^{-2}$ (product was 1.2 times softer), whereas $2 \%$ of dried black currant press cake powder reduces firmness of the product to $247.4 \mathrm{~N} \mathrm{~cm}^{-2}$ (fruit leather was 2 times softer).

\section{Conclusions}

Freeze-dried raspberry and dried black currant press cake powders contain high amounts of phenolic compounds (2846.9 mg $100 \mathrm{~g}^{-1}$ and $2428.2 \mathrm{mg} 100 \mathrm{gg}^{-1}$, respectively). The concentration of anthocyanins in the dried black currant press cake powder was 19 times higher than in the freeze-dried raspberry press cake powder.

The addition of berry press cake powders during the manufacturing of dried fruit leather significantly enhanced its biochemical composition and reduced firmness of the final product.

The highest content of anthocyanins and phenolics compounds was found in the apple/black currant leather with dried black currant press cake powder. The firmness of fruit leather with dried black currant press cake powder was 2 times lower compared to the control sample (fruit leather without press cake additive).

Enrichment of fruit leathers with dried raspberry and black currant press cake powders effectively enhance their polyphenolic composition and increase their antioxidant activity, thus improving functional properties of the product.

\section{References}

1. Anttonen M. J., Karjalainen R. O. (2005) Environmental and genetic variation of phenolic compounds in red raspberry. Journal of Food Composition and Analysis, Vol. 18 (8), p. 759-769.

2. Anttonen M. J., Karjalainen R. O. (2006) High performance liquid chromatography analysis of black currant (Ribes nigrum L.) fruit phenolics grown either conventionally or organically. Journal of Agricultural and Food Chemistry, Vol. 54 (20), p. 7530-7538.

3. Benzie I. F., Strain J. J. (1996) The ferric reducing ability of plasma (FRAP) as a measure of "antioxidant power": the FRAP assay. Analytical Biochemistry, Vol. 239 (1), p. 70-76.

4. Bobinaitė R., Viskelis P., Bobinas Č., Mieželienè A., Alenčikienė G., Venskutonis P. R. (2016) Raspberry marc extracts increase antioxidative potential, ellagic acid, ellagitannin and anthocyanin concentrations in fruit purees. LWT-Food Science and Technology, Vol. 66, p. 460-467.

5. Bobinaite R., Viškelis P., Šarkinas A., Venskutonis P. R. (2013) Phytochemical composition, antioxidant and antimicrobial properties of raspberry fruit, pulp, and marc extracts. CyTA-Journal of Food, Vol. 11 (4), p. 334-342.

6. Bobinaitè R., Viškelis P., Venskutonis P. R. (2012) Variation of total phenolics, anthocyanins, ellagic acid and radical scavenging capacity in various raspberry (Rubus spp.) cultivars. Food Chemistry, Vol. 132 (3), p. $1495-1501$.

7. Borges G., Degeneve A., Mullen W., Crozier A. (2010) Identification of flavonoid and phenolic antioxidants in black currants, blueberries, raspberries, red currants and cranberries. Journal of Agricultural and Food Chemistry, Vol. 58 (7), p. 3901-3909.

8. Bordonaba J. G., Terry L. A. (2012) Electrochemical behavior of polyphenol rich fruit juices using disposable screen-printed carbon electrodes: towards rapid sensor for antioxidant capacity and individual antioxidants. Talanta, Vol. 90, p. 38-45.

9. Brand-Williams W., Cuvelier M. E., Berset C. (1995) Use of a free radical method to evaluate antioxidant activity. LWT-Food Science and Technology, No. 28, p. 25-30.

10. Diamante L. M., Bai X., Busch J. (2014) Fruit Leathers: Method of Preparation and Effect of Different Conditions on Qualities (Review Article). Hindawi Publishing Corporation International Journal of Food Science, Vol. 2014, Article ID 139890, 12 p.

11. Gailite I., Strauniece E., Seglina D. (2006) Berry marc in wheat bread production. Chemine Technologija, Vol. 4 (42), p. 43-50.

12. Ghafoor K., AL-Juhaimi F., Yong Hee Choi Y. (2011) Effects of exstracts on phenolics, antioxidants and anthocyanins in grape juice. Pakistan Journal of Botany, Vol. 43 (3), p. 1581-1586.

13. Giusti M. M., Wrolstad R. E. (2003) Acylated anthocyanins from edible sources and their applications in food systems. Biochemical Engineering Journal, Vol. 14 (3), p. 217-225.

14. Górecka D., Pachołek B., Dziedzic K., Górecka M. (2010) Raspberry pomace as a potential fiber source for cookies enrichment. Acta Scientiarum Polonorum Technologia Alimentari, Vol. 9 (4), p. 451-462. 
15. Huang X., Hsieh F.-H. (2005) Physical properties, sensory attributes, and consumer preference of pear fruit leather. Journal of Food Science, Vol. 70 (3), p. 177-186.

16. Klensporf D., Jelen H. H. (2008) Influence of the Addition of raspberry seed extract on changes in the volatile pattern of stored model breakfast cereal. Journal Agricultural and Food Chemistry, Vol. 56 (9), p. 3268-3272.

17. Kruczek M., Drygaś B., Habryka C. (2016) Pomace in fruit industry and their contemporary potential application. World Scientific News, Vol. 48, p. 259-265.

18. Määttä-Riihinen K. R., Kamal-Eldin,A., Törrönen A. R. (2004). Identification and quantification of phenolic compounds in berries of Fragaria and Rubus species (family Rosaceae). Journal Agricultural and Food Chemistry, Vol. 52 (20), p. 6178-6187.

19. McGuire R. G. (1992) Reporting of objective color measurement. HortScience, Vol. 27 (12), p. 1254-1255.

20. Molnar D., Brnčić S. R.,Vujić L., Gyimes E., Krisch J. (2015) Characterization of biscuits enriched with black currant and jostaberry powder. Potravinarstvo, Vol. 9 (1), p. 53-57.
21. Quintero Ruiz N. A., Demarchi S. M., Massolo J. F., Rodoni L. M., Giner S. A. (2012) Evaluation of quality during storage of apple leather. LWT-Food Science and Technology, Vol. 47, p. 485-492.

22. Re R., Pellegrini N., Proteggente A., Pannala A., Yang M., Rice-Evans C. (1999) Antioxidant activity applying an improved ABTS radical cation decolorization assay. Free radical biology and medicine, Vol. 26 (9), p. 1231-1237.

23. Shahidi F. (1997) Natural Antioxidants: Chemistry, Health Effects, and Application. The American Oil Chemists Society. 414 p.

24. Slinkard K., Singleton V. L. (1977) Total phenol analysis: Automation and comparison with manual methods. American Journal of Enology and Viticulture, Vol. 28, p. $49-55$.

25. Tian X. (2016) Food processing by-products as natural sources of antioxidants: a mini review. Adv Journal Nutritional Science and Food Technology, Vol. 2, p. 7-17.

26. Vrhovsek U., Giongo L., Mattivi F., Viola R. (2008) A survey of ellagitannin content in raspberry and blackberry cultivars grown in Trentino (Italy). European Food Research and Technology, Vol. 226 (3), p. 817-824. 